\title{
Synthesis and Characterization of Zinc Oxide (ZnO) Nanowire
}

\section{Igori Wallace ${ }^{1 *}$, Okpashi Victor Eshu ${ }^{2}$, Obi Bonaventure Chukwunonso ${ }^{3}$ and Uchechukwu C Okoro ${ }^{4}$}

${ }^{1}$ Department of Chemistry, College of Education Oju, Benue State, Nigeria

${ }^{2}$ Biochemistry Department, University of Nigeria, Nsukka, Nigeria

${ }^{3}$ Department of Pharmacology and Toxicology, University of Nigeria, Nigeria

${ }^{4}$ Department of Pure, Industrial Chemistry, University of Nigeria, Nigeria

\begin{abstract}
Nanowires are structures that have a lateral size constraint to tens of nanometers or less and an unconstrained longitudinal size. The syntheses and characterization of $\mathrm{ZnO}$ nanowire with hexagonal structure was successfully achieved using chemical bath deposition technique. The nanowires obtained were further characterized by scan electron microscope (SEM), X-ray diffraction (XRD), energy dispersive X-ray analysis (EDX) and spectrophotometer. The SEM micrographs revealed the morphology of $\mathrm{ZnO}$ nanowires with diameter $170.3 \mathrm{~nm}$ and $481 \mathrm{~nm}$. This revealed that the $\mathrm{pH} 8.1$ of the bath solution and the optimized value form $\mathrm{ZnO}$ nanowires with hexagonal shape at top surface. The XRD pattern of the samples revealed $\mathrm{ZnO}$ nanowire have hexagonal crystallite structure. Where upon the crystallite size supported increased annealing temperature $\left(0.536 \mathrm{~nm}, 0.541 \mathrm{~nm}\right.$ and $0.557 \mathrm{~nm}$ at $100^{\circ} \mathrm{C}, 150^{\circ} \mathrm{C}$ and $200^{\circ} \mathrm{C}$ respectively). The EDX analysis revealed the elemental compositions of samples and confirmed the presence of $\mathrm{Zn}$ and O2. The results of the optical analysis showed that $\mathrm{ZnO}$ nanowire have high absorbance in the ultraviolet and infrared regions with high transmittance in the visible region. The absorbance of the nanowire increases with increasing annealing temperature. Its high absorbance in the ultraviolet region suggest it applicability as solar harvester for trapping solar energy, used for photovoltaic panel with capacity to converting sunlight radiation directly to electricity for commercial or industrial purposes.
\end{abstract}

Keywords: Nanowire; Synthesis; Zinc oxide; Characterization and application

\section{Introduction}

A nanowire is a nanostructure, with diameter in the range $\left(10^{-9}\right.$ nanometers). Alternatively, nanowires is defined as structures with diameter constrained to tens of nanometers or less and unconstrained length [1]. At these scales, quantum mechanical effects are important and coined the term quantum wires [2]. Different types of nanowires exist, such as metallic $(\mathrm{Ni}, \mathrm{Pt}, \mathrm{Au})$, semiconducting $(\mathrm{Si}, \mathrm{InP}, \mathrm{GaN}$, $\mathrm{ZnO}$, etc.), and insulator $\left(\mathrm{SiO}_{2}, \mathrm{TiO}_{2}\right)$ [3]. Typical nanowires exhibit ratios (length-to-width ratio) of 1000 or more. They are referred to as one-dimensional (1-D) materials. Nanowires have many interesting properties that are not in bulk or 3-D [4]. This is because electrons in nanowires are quantum confined laterally and occupy energy levels that are different from the traditional continuum of energy levels or bands found in bulk materials [2]. Particular features of this quantum confinement exhibited by certain nanowires usually manifested as discrete values of electrical conductance [5-8]. Such discrete values arose from a quantum mechanical restraint on the number of electrons that can travel through the wire at nanometer scale. $\mathrm{ZnO}$ is a typical II-VI semiconductor material with a wide band-gap 3.37 $\mathrm{eV}$ at room temperature [2]. Although its band-gap value is closer to $\mathrm{GaN}(3.44 \mathrm{eV})$, its exciton binding energy is $39 \mathrm{eV}$, which is higher compared GaN $(25 \mathrm{meV})$ [9,10]. Theoretically, harvesting of high efficient UV exciton emission and laser at room temperature that will prompt the applications of UV laser in the fields of benthal detection, communication and optical memory with magnitude enhancement and performance was achievable [4-15]. The melting point of $\mathrm{ZnO}$ is $1954^{\circ} \mathrm{C}$, this determines high thermal and chemical stability. Again, $\mathrm{ZnO}$ has potentials due to its affordability, abundant in nature, environmentally/eco-friendly, simple fabrication processes and some others [3]. Various physicochemical and electrochemical deposition techniques have been reported to create oriented MOS (metal oxide semiconductor) nanowires [5]. Methods such as catalytic growth via vapor-liquid-solid epitaxial (VSLE) mechanism, metal-organic chemical vapour deposition (MOCVD), pulsed laser deposition (PLD), chemical vapour deposition (CVD), hydrothermal synthesis, solution approaches and electrode position have been particularly successful in creating sensitive oriented arrays of anisotropic nanowires of $\mathrm{ZnO}$ $[12,13]$. In general, there are two distinct approaches to creating nanowires: top-down and bottom-up strategies [13]. The top-down approach usually including etching and lithography in bulk materials to form functional devices, this approach has been successful in many venues [16]. In the bottom-up approach, functional nanostructures are assembled from well-defined chemically and/or physically synthesized building blocks. Zinc oxide nanowires are commonly synthesized by a bottom-up approach [17]. CVD is a widely used route to produce high-purity, high-performance materials [7]. In the CVD method, the precursor gases are first delivered into a reaction chamber at approximately ambient temperatures [18-20]. In the reaction chamber a heated substrate or a wafer is used to expose volatile precursors, which react and decompose the substrate surface to produce desired solid phase. The by-products are removed by gas flow through the reaction chamber [10]. Commonly, CVD is a generic name for a group of processes that involve depositing a solid material from a gaseous phase. CVD processes include: atmospheric pressure CVD (APCVD), low-pressure CVD (LPCVD), vapour phase epitaxy (VPE), chemical beam epitaxy (CBE), and metal-organic chemical vapour deposition (MOCVD) [21]. Hydrothermal syntheses are another convenient

*Corresponding author: Igori Wallace, Department of Chemistry, College of Education Oju, Benue State, Nigeria, Tel: 044-661296; E-mail: igoriwallace@gmail.com

Received June 20, 2015; Accepted August 07, 2015; Published October 01, 2015

Citation: Wallace I, Eshu OV, Chukwunonso OB, Okoro UC (2015) Synthesis and Characterization of Zinc Oxide ( $\mathrm{ZnO})$ Nanowire. J Nanomed Nanotechnol 6: 321. doi:10.4172/2157-7439.1000321

Copyright: @ 2015 Wallace I, et al. This is an open-access article distributed under the terms of the Creative Commons Attribution License, which permits unrestricted use, distribution, and reproduction in any medium, provided the original author and source are credited. 
method to synthesis semiconductor nanowires. For example $\mathrm{ZnO}$ nanowires can be obtained by the hydrolysis of zinc nitrate in water in the presence of amine $[13,22]$. The zinc (II) is solvated by water, and exists as several monomeric hydroxyl species, such as $\mathrm{Zn}(\mathrm{OH})^{+}$ (aq), $\mathrm{Zn}(\mathrm{OH})_{2}(\mathrm{aq})$, and $\mathrm{Zn}(\mathrm{OH})_{4}{ }^{2-}[6,23-25]$. The stability of these complexes is depends on the $\mathrm{pH}$ and temperature of the solution. Solid $\mathrm{ZnO}$ nuclei are formed by the dehydration of these hydroxyl species, shown in equation 1 . Additives to the solution mixture, often amines, have strong effect on the morphology of the resulting crystal [25].

$$
\mathrm{Zn}(\mathrm{OH})_{2(\mathrm{aq})} \rightarrow \mathrm{ZnO}_{(\mathrm{s})}+\mathrm{H}_{2} \mathrm{O}_{(\mathrm{aq})}
$$

Finally, electrode position has three attributes that makes it promising technique for fabrication of nanowires. First, it is used to grow functional materials through complex $2 \mathrm{D}$ or $3 \mathrm{D}$ templates; second, it can performed at temperature near room temperature from water-based electrolyte solutions; and it is scaled down to deposition of few atoms up to wider dimensions [3,25]. Electrode position within anodic alumina membrane templates is a bottom-up synthesis route which has been used with considerable success by numerous groups to synthesize metal and semiconductor [26-33]. In synthesizing, a piece of anodic aluminum oxide (AAO) membrane with highly ordered nanopores is used as growth template. The dimensions of the nanopores varied over a large length scale. Another promising method to synthesize Zinc oxide nanowires is physical vapour deposition (PVD). PVD is a technique similar to CVD, except that there is no chemical reaction happening during the deposition process. Variants of PVD include pulse laser deposition (PLD), and sputter deposition. These methods produce high-quality, single crystalline wires. However, these processes require elevated temperatures of $450-900^{\circ} \mathrm{C}$ and face other limitations of sample uniformity and substrate choice $[10,28,31]$. Wang and co-workers have examined the synthesis, structure analysis and properties of nanoscale zinc oxide. They used solid-vapour thermal sublimation techniques to synthesize $\mathrm{ZnO}$ nanowires, nanobelts, nanorings, nanocages, and nanocombs [32]. Zinc oxide nanowires and nanorods could be synthesized in many routes, such as vapourliquid-solid (VLS) growth. In this technique, a metal catalyst, such as $\mathrm{Au}$ or $\mathrm{Sn}$, was chosen and serves as the site for adsorbing the incoming molecules ( $\mathrm{Zn}$ complexes). A liquid alloy droplet composed of metal catalyst was formed, followed by addition of the gaseous precursor to form an AuZn alloy [2-30]. The metal liquid droplet serves as a preferential site for absorption of gas-phase reactant. Nanowire growth begins after the liquid becomes supersaturated in reactant materials and continues as long as the catalyst alloy remains in a liquid state and the reactant [34]. The nanowire growth terminates when the temperature is below the eutectic temperature of the catalyst alloy or the reactant is no longer available. In contrast to gas-phase technologies, solution approaches are appealing because of the low growth temperature $\left(<350^{\circ} \mathrm{C}\right)$, potential for scaling up, and straight-forward methods of producing high-density arrays. Chemical bath deposition (CBD) is one of the useful solution methods for the preparation of compound semiconductors from aqueous solution, with advantages such as low processing temperature, allowing growth of variety of substrates, and easy adaptation to large area processing at low fabrication cost [35-40]. Only $2 \%$ of the reagents in the solution is used during CBD growth $[12,41]$ has prepared highly (0001)-oriented $\mathrm{ZnO}$ films by UV lightassisted CBD from an aqueous solution containing hydrated zinc nitrate and dimethylamineborane (DMAB). A recent report has shown that the $\mathrm{CBD}$ method can be used to synthesize $\mathrm{ZnO}$ films and nanorod arrays on different substrate $[40,42]$ has prepared $\mathrm{ZnO}$ nanowire with CBD using silicon substrate and found the average diameter of the nanowire to be $125 \mathrm{~nm}$ [29]. Therefore, $\mathrm{ZnO}$ has become a focus in the field of short-wavelength laser and optoelectronic devices in succession to $\mathrm{GaN}$ in the past decade. It is believed by some researchers that $\mathrm{ZnO}$ is a more prospective candidate for the next generation of light emitters for solid state lighting applications than GaN, even though the GaN-based LEDs has been commercialized and currently dominate the light emission applications in UV/blue wavelength range. This is because $\mathrm{ZnO}$ has several advantages compared to $\mathrm{GaN}$. The following outstanding qualities: The exciton binding energy of $\sim 60 \mathrm{meV}$ at room temperature is higher than $\mathrm{GaN}(\sim 25 \mathrm{meV})$, which can enhance the luminescence efficiency of $\mathrm{ZnO}$ based light emission devices at room temperature and lower the threshold for lasing by optical pumping $[17,26]$. The growth of high quality single crystal substrates is easier and of lower cost than GaN $[8,30]$. The advent of Nano technology and nanowire fabrication marked a new epoch in optoelectronics [1]. An investigation to achieving efficient light absorption, charge separation transport and collection gave credence to the synthesis of organic and inorganic semiconductor nanowires $[2,3]$. The d-block transition elements are metals of industrial and economic relevant. Zinc, which is a group II element, finds numerous potential applications, such as smart windows, solar thermal absorber, optical memories and photoelectrocatalysis $[4,5]$. Recently, the products of semiconductor industry spread all over the world and deeply penetrate into the daily life of humans. The starting point of semiconductor industry was the invention of the first semiconductor transistor in 1947 [3]. Since then, the semiconductor industry has grown with tremendous benefit. In the 1949's, the information age of humans had started on the basis of the stepwise appearance of quartz optical fiber, group III-V compound semiconductors and gallium arsenide (GaAs) lasers. During the development of the information age, silicon (Si) keeps the dominant place on the commercial market, which is used to fabricate the discrete devices and integrated circuits for computing, data storage and communication. Since Si has an indirect band-gap that is disadvantage in optoelectronic devices such as light emitting diodes (LEDs) and laser diodes. GaAs with direct band-gap stands out and fills the blank for this application. As the development of information technologies continued, the requirement for ultraviolet (UV)/blue light emitter applications became intensified which is beyond the limits of GaAs. Therefore, the wide band-gap semiconductors such as gallium nitride $(\mathrm{GaN})$ and zinc oxide $(\mathrm{ZnO})$, i.e. the third generation semiconductors, came into focus with researcher's interest in the field of semiconductor. Literature have shown that, man depend majorly on non-renewable energy source (coal, fossil fuel and natural gas) as the primary energy source. However, the energy generated from these source are nonenvironmentally friendly, costly, and limited in quantity because nature does not produce them at the same rate that they are being consumed and are bound to expire in a while. Based on this, it is imperative to search for a more abundant, environmentally friendly, clean, cheap and sustainable energy source [43].

In view of these, the optical property of $\mathrm{ZnO}$ nanowire was investigated to find its potency as solar harvester as renewable energy for industrial and commercial purpose. Bulk particles have some hidden properties which cannot be harnessed but at Nano scale, these properties can be revealed. In view of this, nanowire with enhanced optical and electrical properties was synthesis from bulk particles [43]. These properties at Nano scale find use in varied areas of life. The need for abundant, free energy source coupled with the desirability of obtaining nanoparticles from their counterpart bulk materials with enhanced properties culminated into this study. 


\section{Methods}

\section{Materials}

In this work, chemical bath deposition method (CBD) was used for the growth of $\mathrm{ZnO}$ nanowire. The growth temperature was $50^{\circ} \mathrm{C}$. The properties of the deposited material were varied and controlled via optimization of chemical baths.

\section{Chemicals}

All chemicals were analytical grade reagents and used without further purification. All the aqueous solutions were prepared using distilled water. The synthesis of $\mathrm{ZnO}$ nanowire combines substrate pretreatment and CBD growth.

\section{Substrate preparation}

Prior to deposition of $\mathrm{ZnO}$ nanowire, glass micro slides were chemically degreased by treatment with dilute $\mathrm{HCl}$ for 24 hours and later cleaned with detergent/cold water and rinsed with distilled water and allowed to drip to dryness in air.

\section{Substrate pretreatment}

A quantity of $10 \mathrm{~mL}$ each of zinc acetate dihydrate $\mathrm{Zn}$ $\left.\left(\mathrm{OOCCH}_{3}\right)_{2} .2 \mathrm{H}_{2} \mathrm{O}\right](0.05 \mathrm{M})$ and ethanol $(0.05 \mathrm{M})$ were mixed in a $50 \mathrm{~mL}$ beaker. This solution was coated on glass substrates by spin coater (Laurell WS-400-STFW-FULL) at rate of $2000 \mathrm{rmp}$ for 30s. The thickness of the zinc acetate layer can be controlled by the number of spin coating runs and show good reproducibility. Here, substrates were spin coated twice. The coated substrates were dried at room temperature and annealed at $150^{\circ} \mathrm{C}$ for $30 \mathrm{~min}$. All the substrates were pretreated twice before the final growth of $\mathrm{ZnO}$ nanowire.

\section{Chemical Bath Deposition (CBD) growth}

For CBD growth process, the aqueous solution of zinc nitrate hexahydrate and hexamine were first prepared. The concentrations of both were fixed at $0.1 \mathrm{M}$. Aqueous solutions of zinc nitrate hexahydrate $(20 \mathrm{~mL})$ and hexamine $(20 \mathrm{~mL})$ were mixed together in $50 \mathrm{~mL}$ beaker. Aqueous ammonia $(0.1 \mathrm{M})$ was added to the solution to vary the $\mathrm{pH}$. The amount added depends on the targeted $\mathrm{pH}$. In this work, 4-6 $\mathrm{ml}$ of aqueous ammonia was added to raise the $\mathrm{pH}$ to 9.00 and 10.0 respectively. The $\mathrm{pH}$ of the original growth solution was 8.1 .

\section{Observation step 1}

The original growth solution $(\mathrm{pH}$ of 8.1) was transparent and contains white dispersed precipitates of $\mathrm{Zn}(\mathrm{OH})_{2}$. The bath solutions at pH 9.0 and 10.0 dissolved and appeared white turbid in nature (milky). The pretreated glass slides (substrates) were immersed into the three different bath solutions and tilted against the wall of the beaker. The beakers containing the bath solutions and the substrates were put in the oven for $2 \mathrm{~h}$ at a constant temperature of $93^{\circ} \mathrm{C}$. After the growth, the substrates were removed from the solutions, rinsed with distilled water and then dried at room temperature.

\section{Observation step 2}

A white dense and uniform deposition was observed on the samples grown at the $\mathrm{pH}$ 8.1. While the less dense milky deposition was observed on the samples grown at $\mathrm{pH} 9.0$ and slightly transparent white deposition was observed on samples grown at $\mathrm{pH}$ 10.0.

\section{Post growth annealing}

A post growth thermal annealing was performed for the substrates (samples) from the three different $\mathrm{pH}(\mathrm{s})$ solutions $(8 ; 9 ; 10)$ at $100^{\circ} \mathrm{C}$, $150^{\circ} \mathrm{C}$ and $200^{\circ} \mathrm{C}$ respectively for $1 \mathrm{~h}$ and then quenched to room temperature by removal from the oven (Table 1).

\section{Results and Discussion}

Chemical determination of this research was carried out with deposition of metal oxide semiconducting nanowire, which occurs via the maintenance of substrate and metal ions in contact with chemical bath. Nanowire formation with substrate occur when the solution attained saturation such that the ionic product of anion and cation exceeds the solubility product of the reaction. Precipitation can be carried out in the bath using substrate [44]. Also, [10,28,33] worked on synthesis of Zinc tetramine using Hexamethyltetramine (HMT) which was responsible for the production of ammonia $\left(\mathrm{NH}_{3}\right)$ that played the role of complexion agent. That is, complexion agent aided the yield of Zinc tetramine $\left(\mathrm{Zn}\left(\mathrm{NH}_{3}\right)_{4}{ }^{2+}\right)$ complex ion in alkaline medium. The reaction that occurs in the bath is shown in the chemical equations:

$$
\begin{aligned}
& \left(\mathrm{CH}_{2}\right)_{6} \mathrm{~N}_{4}+6 \mathrm{H}_{2} \mathrm{O} \rightarrow 6 \mathrm{HCHO}+4 \mathrm{NH}_{3} \\
& \mathrm{NH}_{3}+\mathrm{H}_{2} \mathrm{O} \rightarrow \mathrm{NH}_{4}^{+}+\mathrm{OH}^{-} \\
& \mathrm{Zn}\left(\mathrm{NO}_{3}\right)_{2} \rightarrow \mathrm{Zn}_{2}++2 \mathrm{NO}^{3-} \\
& \mathrm{NO}_{3}{ }^{-}+\mathrm{H}_{2} \mathrm{O}+2 \mathrm{e}^{-} \rightarrow \mathrm{NO}_{2}{ }^{-}+2 \mathrm{OH}^{-} \\
& \mathrm{Zn}_{2}{ }^{+}+2 \mathrm{OH}^{-} \rightarrow \mathrm{Zn}(\mathrm{OH})_{4}{ }^{2-} \\
& \mathrm{Zn}_{2}++4 \mathrm{NH}_{3} \rightarrow \mathrm{Zn}\left(\mathrm{NH}_{3}\right)_{4}{ }^{2+} \\
& \mathrm{Zn}\left(\mathrm{NH}_{3}\right)_{4}{ }^{2+}+2 \mathrm{OH}-\rightarrow \mathrm{ZnO}+4 \mathrm{NH}_{3}+\mathrm{H}_{2} \mathrm{O} \\
& \mathrm{Zn}(\mathrm{OH})_{4}{ }^{2-} \rightarrow \mathrm{ZnO} \text { cluster }+\mathrm{H}_{2} \mathrm{O}+2 \mathrm{OH}^{-}
\end{aligned}
$$

In the chemical solution, the hexamethyltetramine is first hydrolyzed (Equation 2). $\mathrm{NO}_{3}^{-}$ions acquire electrons and reduced to $\mathrm{NO}_{2}^{-}$ions, inducing the increase of $\mathrm{OH}^{-}$concentration (Equation 5) [36]. More and more $\mathrm{OH}^{-}$ions combined with $\mathrm{Zn}^{2+}$ ions to form an intermediate growth unit of $\mathrm{Zn}(\mathrm{OH})_{4}{ }^{2-}$ (Equation 6). Due to dehydration of the complex in the alkaline medium, $\mathrm{ZnO}$ clusters are formed by the electrostatic attraction of ionic species $\left(\mathrm{Zn}^{2+}\right.$ and $\mathrm{OH}^{-}$) (Equations 8 and 9). It is well-known that super saturation is a prerequisite for crystal growth in solution and is also intimately connected with growth processes involved in the evolution of crystal morphology [14]. As the reactions continue, more $\mathrm{ZnO}$ clusters appear in solution. When the solution become supersaturated, nucleation cluster of molecules formed undergo rapid decomposition and particles combine to produce film thickness, where $\mathrm{ZnO}$ nanowire formed in the solution via substrate. The morphological analysis (surface structure) of the deposited $\mathrm{ZnO}$ nanowire was carried out using scan electron microscope. The nanowires grown at $\mathrm{pH} 8.1$, possesses hexagonal shape and the diameters was measured at different angles $90^{\circ}$ and

\begin{tabular}{|c|c|c|}
\hline $\mathbf{0}$ & Growth $\mathbf{~ p H}$ & Annealing temperature $\mathbf{~}^{\circ} \mathbf{C}$ ) \\
\hline W8100 & 8.1 & 100 \\
\hline W8150 & 8.1 & 150 \\
\hline W8200 & 8.1 & 200 \\
\hline W9100 & 9 & 100 \\
\hline W9150 & 9 & 150 \\
\hline W9200 & 9 & 200 \\
\hline W10100 & 10 & 100 \\
\hline W10150 & 10 & 150 \\
\hline W10200 & 10 & 200 \\
\hline & Table 1: Characterization of samples. \\
\hline
\end{tabular}


Citation: Wallace I, Eshu OV, Chukwunonso OB, Okoro UC (2015) Synthesis and Characterization of Zinc Oxide (ZnO) Nanowire. J Nanomed Nanotechnol 6: 321. doi:10.4172/2157-7439.1000321

$132.3^{\circ}$ across the breadth of the nanowire between two points ( $\mathrm{Pa} 1$ and PaR1) and was found to be between 170.3 and $481 \mathrm{~nm}$ as shown in Figures 1-4 below similarly, the samples grown at $\mathrm{pH} 9.0$ and 10.0 were observed to be nanostructures with tapered flower-like shape as

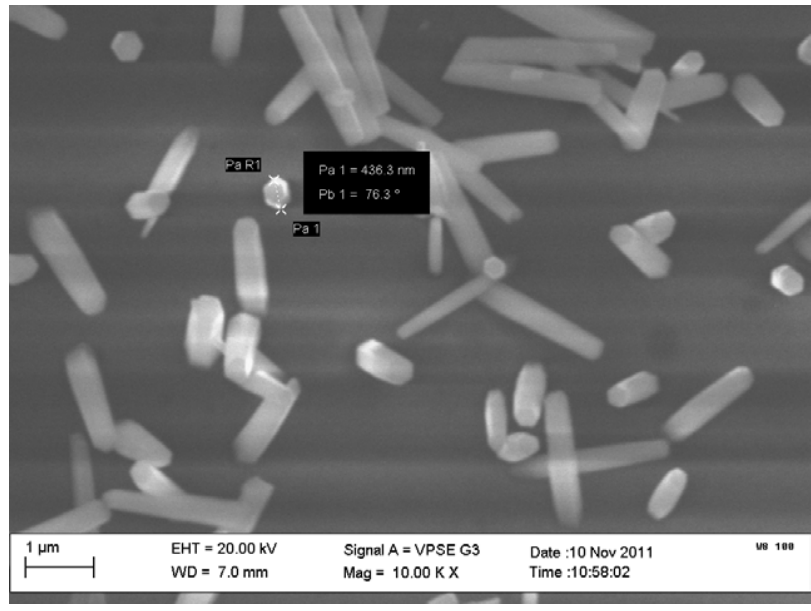

Figure 1: SEM of $\mathrm{W} 8100$ grown at $\mathrm{pH} 8.1$ and annealed at $100^{\circ} \mathrm{C}$

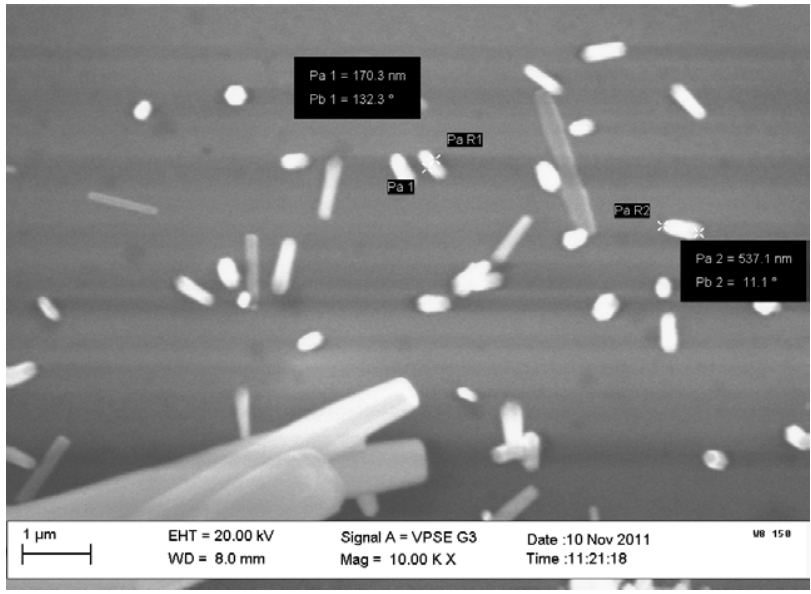

Figure 2: SEM of $\mathrm{W} 8150$ grown at $\mathrm{pH} 8.1$ and annealed at $150^{\circ} \mathrm{C}$

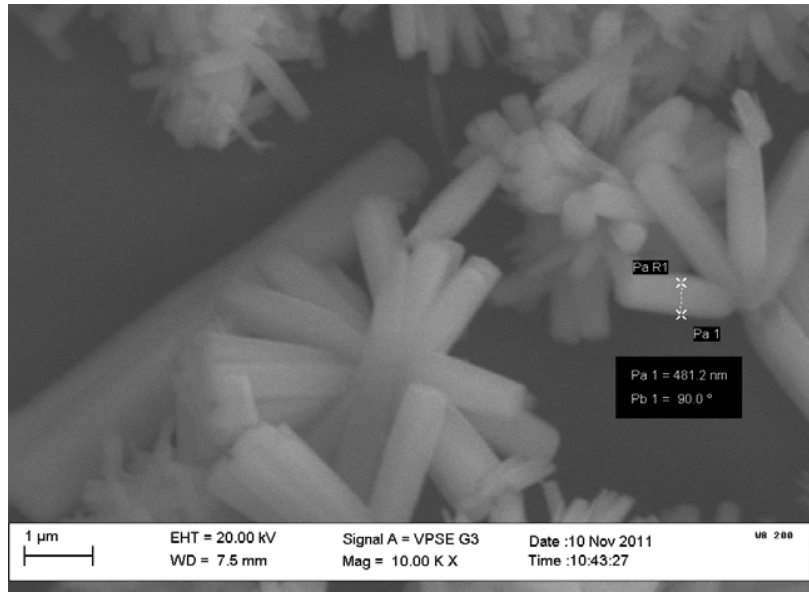

Figure 3: SEM of W8200 grown at $\mathrm{pH} 8.1$ and annealed at $200^{\circ} \mathrm{C}$

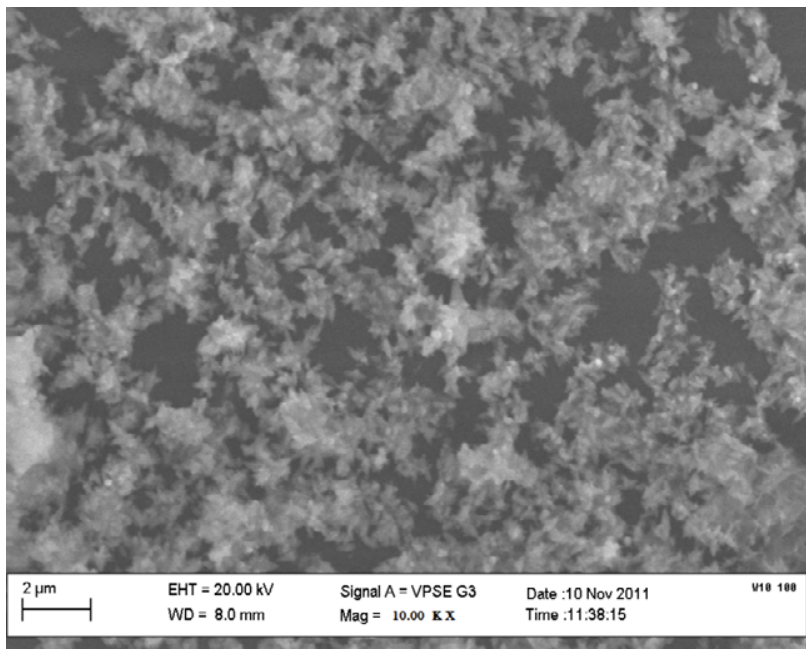

Figure 4: SEM of W9100 grown at $\mathrm{pH} 9.0$ and annealed at $100^{\circ} \mathrm{C}$

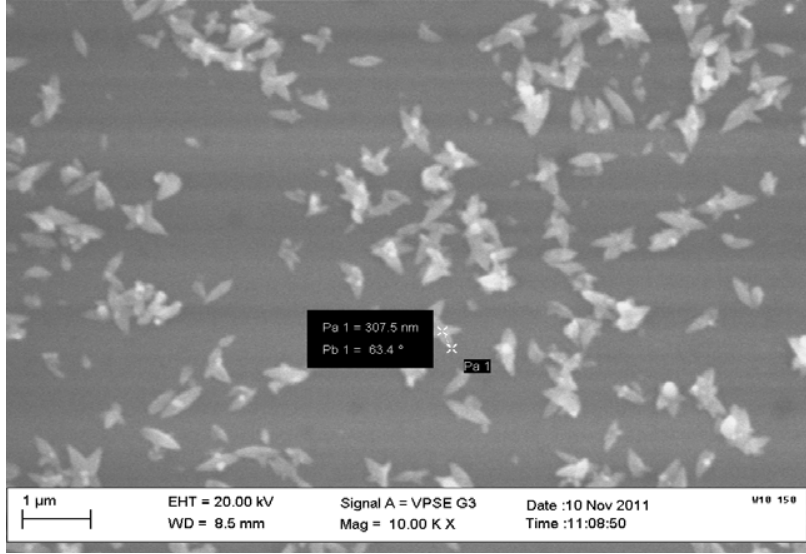

Figure 5: SEM of W9150 grown at pH 9.0 and annealed at $150^{\circ} \mathrm{C}$

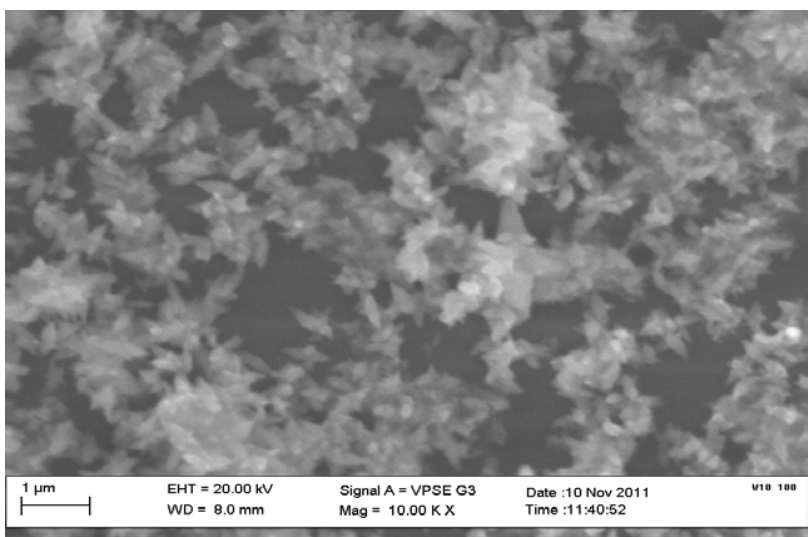

Figure 6: SEM of W9200 grown at $\mathrm{pH} 9.0$ annealed at $200^{\circ} \mathrm{C}$.

shown in Figures 5-9 below. This shape transformation was due to the competition between growth and erosion. As is well known, the hexagonal wurtzite $\mathrm{ZnO}$ crystal is a typical polar crystal with a dipole moment in the direction of c-axis, the 0001 crystal plane represents the polarity and is metastable, but the side planes are non-polar and 
Citation: Wallace I, Eshu OV, Chukwunonso OB, Okoro UC (2015) Synthesis and Characterization of Zinc Oxide (ZnO) Nanowire. J Nanomed Nanotechnol 6: 321. doi:10.4172/2157-7439.1000321

Page 5 of 9

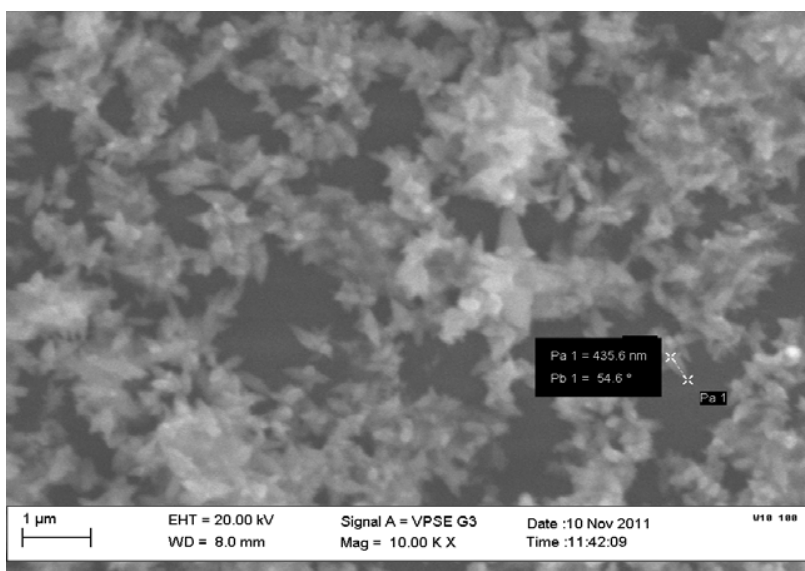

Figure 7: SEM of $\mathrm{W} 10150$ grown at $\mathrm{pH} 10$ and annealed at $150^{\circ} \mathrm{C}$

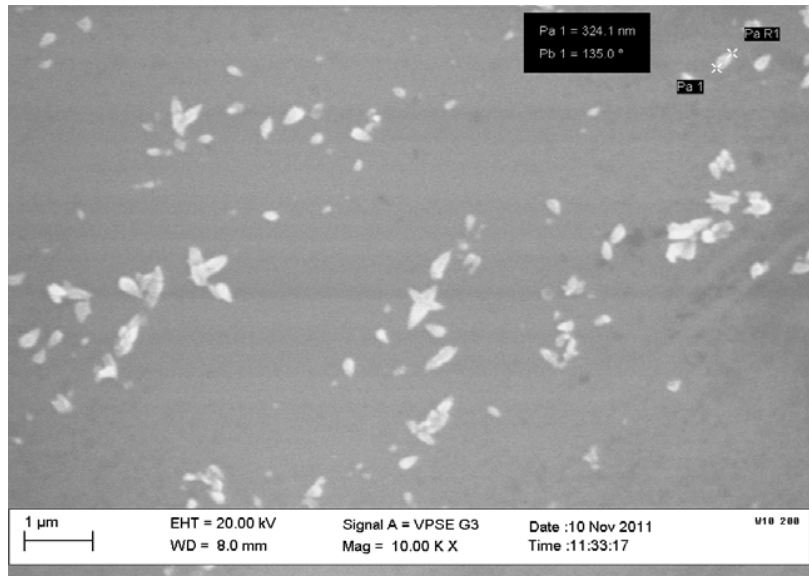

Figure 8: SEM of $\mathrm{W} 10200$ grown at $\mathrm{pH} 10.0$ and annealed at $200^{\circ} \mathrm{C}$.

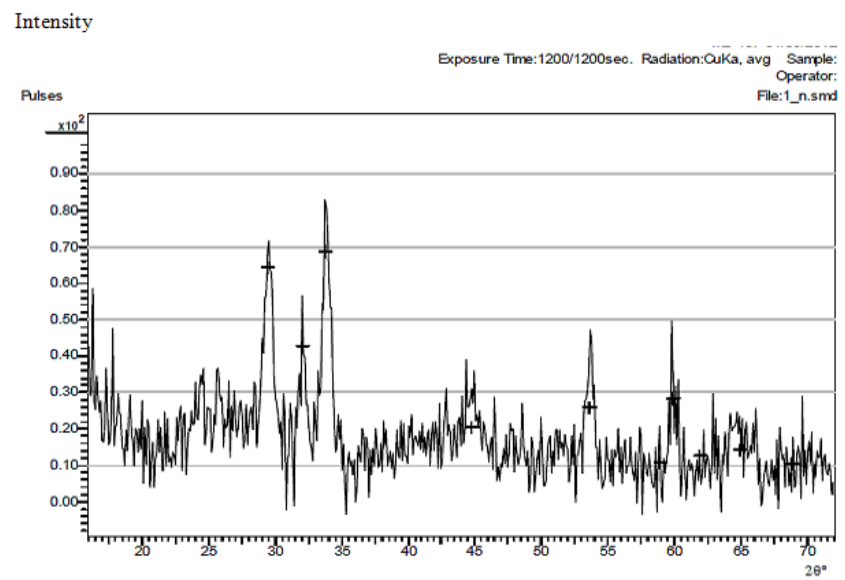

Figure 9: Chromatogram of X-Ray diffraction pattern of W8100.

relatively stable. The polar top planes are able to attract hydroxyl ion (OH-), which could erode the planes in solution as illustrated in equation 10 below:

$$
\mathrm{ZnO}+\mathrm{OH}^{-} \rightarrow \mathrm{ZnO}_{2}^{2-}+\mathrm{H}_{2} \mathrm{O}
$$

More so, the original growth solution, the $\mathrm{OH}^{-}$in solution is enough to grow the nanowires. Upon the addition of aqueous ammonia, $\mathrm{OH}$ was formed when the solution was heated so that the total amount of $\mathrm{OH}^{-}$was not consumed completely during the growth. The rest of the $\mathrm{OH}^{-}$in solution took part in the erosion reaction at same time. The relative erosion process became intensive as the $\mathrm{pH}$ was increased. However, during the CBD growth phase, the growth rate was faster than the erosion rate. This was due to the competition between growth and erosion, the top of $\mathrm{ZnO}$ nanowires become tapered at $\mathrm{pH} 9.0$ and 10.0.

The SEM micrographs showed the growth rate as $\mathrm{pH}$ was increased from initial $\mathrm{pH} 8.1$ of the solution. The morphology or shape of the nanowire changes from hexagonal structure to tapered flower-like structure. Therefore, the original $\mathrm{pH} 8.1$ of the solution was optimized to form $\mathrm{ZnO}$ nanowires with the top surface of hexagonal shape. X-ray diffraction analysis (XRD) was carried out for samples grown at $\mathrm{pH}$ 8.1, in order to study the crystalline nature of the deposited nanowires, the XRD patterns were recorded in the $2 \theta$ ranging from $10-70^{\circ}$ with $\mathrm{CuK}_{2}(\lambda=1.5406 \AA)$ and the intensity was plotted against $2 \theta$. The XRD diffraction pattern and peak related values of annealed nanowires are shown in Tables 2 and 3 which correlate the angular diffraction at $2 \theta$ range with $\mathrm{ZnO}$, while Tables 4 and 5 indicates three peaks at $2 \theta$ values $33.77,44.82$ and 53.63 for sample W8100 matched, two peaks at a $2 \theta$ value of 44.88 and 66.40 for sample W8150 matched and three peaks at $2 \theta$ value of 31.82, 56.68 and 67.96 matched for sample W8200 (Figures 10 and 11$)$.

The average crystallite sizes of the nanowires were deduced by the inverse proportional relation of the full width at half maximum (FWHM), as predicted by Debye-Scherrer's $[D=0.9 \lambda / \beta \cos \theta]$ Equation $11 \mathrm{D}$ is the crystalline size, $\lambda$ is the $\mathrm{X}$-ray wavelength used (1.5406 $\AA$ ), $\beta$ is the full width at half maximum (FWHM) intensity, and $\theta$ is the Bragg's angle (diffraction angle).

For W8100, the three peaks at $2 \theta$ that matched with corresponding FWHM are 33.77, 44.82, and 53.63 at $0.28912,0.27997$ and 0.27168 respectively.

\section{At $\theta=33.77$,}

$D=0.9 \lambda / \beta \cos \theta=0.9 \times 1.5406 /(0.28912 \cos (33.77 / 2))=5.0127 \AA=0.50127 \mathrm{~nm}$

$$
\begin{aligned}
& \text { At } \theta=44.82, \\
& \begin{array}{l}
\mathrm{D}=0.9 \lambda / \beta \cos \theta=\frac{0.9 \times 1.5406}{0.27997 \cos \left(\frac{44.92}{2}\right)} \\
=5.357 \AA=0.5357 \mathrm{~nm} \AA
\end{array}
\end{aligned}
$$

$$
\begin{aligned}
& \text { At } \theta=53.63, \\
& D=0.9 \lambda / \beta \cos \theta=\frac{0.9 \times 1.5406}{0.27168 \cos \left(\frac{52.63}{2}\right)}
\end{aligned}
$$

\begin{tabular}{|l|c|c|c|c|c|c|}
\hline $\mathbf{2 \theta ^ { \circ }}$ & $\mathbf{d}$ & $\mathbf{I}_{\text {int }}$ & $\mathbf{I}_{\max }$ & $\mathbf{I}_{\text {rel }}$ & $\mathbf{I}_{\text {corr }}$ & FWHM \\
\hline 29.44 & 3.03343 & 1317 & 63 & 93.2 & 97.4 & 0.28961 \\
\hline 32.02 & 2.79508 & 870 & 41.7 & 61.6 & 62.6 & 0.28941 \\
\hline 33.77 & 2.65379 & 1413 & 67.7 & 100 & 100 & 0.28912 \\
\hline 44.82 & 2.0223 & 404 & 19.4 & 28.6 & 26.7 & 0.27997 \\
\hline 53.63 & 1.70895 & 519 & 24.8 & 36.7 & 33.2 & 0.27168 \\
\hline 58.9 & 1.56791 & 199 & 9.5 & 14.1 & 12.6 & 0.28105 \\
\hline 59.89 & 1.5444 & 564 & 27 & 39.9 & 35.6 & 0.283 \\
\hline 61.87 & 1.49955 & 239 & 11.5 & 16.9 & 15 & 0.28115 \\
\hline 64.91 & 1.43644 & 272 & 13 & 19.2 & 17 & 0.27828 \\
\hline 68.77 & 1.365 & 193 & 9.2 & 13.7 & 12 & 0.28039 \\
\hline
\end{tabular}

Table 2: X-Ray Diffraction pattern of W8100. 
Citation: Wallace I, Eshu OV, Chukwunonso OB, Okoro UC (2015) Synthesis and Characterization of Zinc Oxide (ZnO) Nanowire. J Nanomed Nanotechnol 6: 321. doi:10.4172/2157-7439.1000321

Page 6 of 9

\section{$\mathrm{ZnO}$}

Zinc Oxide

Zincite, Syn

Rad:CuKal

Cut off:

Lambda: 1.540598

Filter: Monochromator crystal used

dsp: Diffractometer

Ref: McMurdie $\mathrm{H}$, et al.

Sys:Hexagonal

a:3.24982 \pm 9E-5 Int:Diffractometer I/Icor:

a:

Ref 2

\begin{tabular}{l|l}
\hline Dx & Dm: 5.675
\end{tabular}

عa: $\quad \eta \omega \beta: 2.013$

\begin{tabular}{l|l|} 
& S.G.: P63mc \\
\hline b: & c: $5.20661 \pm 0.00015$
\end{tabular}

ß: $\quad$ y:

Y: $\quad$ Z-2

\begin{tabular}{l|l|l}
$\mathrm{mp}$ & $\mathrm{mp}$ \\
\hline
\end{tabular}

Ref 3

Color: Colorless

The sample was obtained from the New Jersey Zinc Co., Bethlehem, PA, USA. The structure was determined by Bragg [1] and refined by Abrahams Bernstein [2]. A high pressure cubic $\mathrm{NaCl}$ type of $\mathrm{ZnO}$ is reported by Bates et al. [3] and a cubic, sphalerite type is reported by Radczewski, Schichi [4]. The approximate temperature of data collection was $26^{\circ} \mathrm{C}$.

Table 3: X-Ray diffraction pattern of zinc oxide quality.

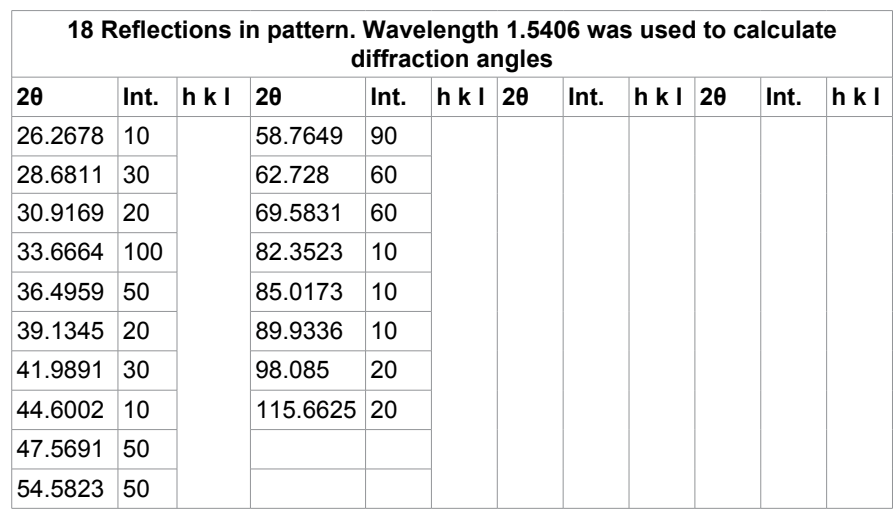

Table 4: Compound phase of W8100.

\begin{tabular}{|c|c|c|c|c|c|c|}
\hline $\mathbf{2 \boldsymbol { \theta } ^ { \circ }}$ & $\mathbf{d}$ & $\mathbf{I}_{\text {int }}$ & $\mathbf{I}_{\text {max }}$ & $\mathbf{I}_{\text {rel }}$ & $\mathbf{I}_{\text {corr }}$ & FWHM \\
\hline 29.55 & 3.02248 & 2874 & 78.6 & 56.8 & 59.4 & 0.50496 \\
\hline 32.14 & 2.78467 & 2140 & 46.8 & 42.3 & 43 & 0.6314 \\
\hline 33.91 & 2.64385 & 5057 & 101.9 & 100 & 100 & 0.68424 \\
\hline 44.88 & 2.01943 & 1241 & 25.1 & 24.5 & 22.9 & 0.6604 \\
\hline 53.61 & 1.70932 & 1435 & 39.2 & 28.4 & 25.7 & 0.47297 \\
\hline 59.7 & 1.54875 & 1343 & 36.7 & 26.6 & 23.7 & 0.49359 \\
\hline 59.9 & 1.54411 & 1318 & 36.1 & 26.1 & 23.3 & 0.49411 \\
\hline 64.72 & 1.44027 & 1576 & 23.6 & 31.2 & 27.6 & 0.89159 \\
\hline 65.52 & 1.42456 & 402 & 7.4 & 8 & 7 & 0.72851 \\
\hline 66.4 & 1.4078 & 453 & 7.7 & 9 & 7.9 & 0.78728 \\
\hline
\end{tabular}

Table 5: X-Ray diffraction pattern of W8150

$$
=5.720 \AA=0.572 \mathrm{~nm}
$$

Average crystallite size for W8100 $=0.50127+0.5357+0.572) / 3=0.536 \mathrm{~nm}$

Also, $[\mathrm{d}=\mathrm{n} \lambda / 2 \sin \theta$ ]

The average crystallite sizes for W8150 and W8200 were similarly deduced and the results are shown in the Table 6.

The result from the table shows that the average crystallite size increases with increase in annealing temperature. The X-Ray Diffraction analysis shows that $\mathrm{ZnO}$ nanowire has a hexagonal crystallite structure with lattice parameters; $a=0.3296, b=0.3296$ and $c=0.52065(a=b \neq c)$ as shown in Table 6 above which agrees with the condition for a lattice structure to be hexagonal. The inter-planar spacing (d) which is the

\begin{tabular}{|c|c|c|}
\hline Sample & Annealing temparature $\left({ }^{\circ} \mathbf{C}\right)$ & Average crystallite size (nm) \\
\hline W8100 & 100 & 0.536 \\
\hline W8150 & 150 & 0.541 \\
\hline W8200 & 200 & 0.557 \\
\hline \multicolumn{2}{|c|}{ Table 6: Crystallite sizes. } \\
\hline
\end{tabular}

\begin{tabular}{|c|c|c|}
\hline Bragg's angle $\boldsymbol{\theta}$ & d-observed & d-calculated \\
\hline 16.89 & 2.653 & 2.652 \\
\hline 22.41 & 2.022 & 2.02 \\
\hline 26.82 & 1.708 & 1.707 \\
\hline
\end{tabular}

Table 7: Inter-planar spacing.

\begin{tabular}{|l|c|}
\hline Element & Weight (\%) \\
\hline Oxygen (O) & 36.28 \\
\hline Aluminum (Al) & 0.72 \\
\hline Silicon (Si) & 26.59 \\
\hline Potassium (K) & 0.55 \\
\hline Calcium (Ca) & 3.5 \\
\hline Zinc (Zn) & 29.16 \\
\hline Sodium (Na) & 1.06 \\
\hline Magnesium (Mg) & 2.14 \\
\hline
\end{tabular}

Table 8: Elemental composition.

distance between the lattices structures on a plane were calculated for sample grown at $\mathrm{pH} 8.1$ using Bragg's law for confirmation as shown in equation 12 Where, $d=$ interpanar spacing, $\mathrm{n}=1$ for simple lattice structure, =X-ray wavelength used (1.5406 $\AA$ ), $\theta=$ Bragg's angle (diffraction angle).

The inter-planar spacing (d-observed) from the table above is the inter-planar spacing observed by the diffractometer and dcalculated is the inter-planar spacing calculated for confirmation. The results from the table above show that there is no significant difference between the $\mathrm{d}$ - observed and $\mathrm{d}$ - calculated in Table 7 . The optical analysis and properties of $\mathrm{ZnO}$ nanowires grown at $\mathrm{pH}$ of 8.1 and 9.0 were characterized using (UNICO-UV-Vis-NIR 2120 PC) spectrophotometer in the range of 172.8-1100 nm (Figures 12 and 13).

The plot of absorbance versus wavelength as shown in Figures 1421 shows that $\mathrm{ZnO}$ nanowire has high absorbance in ultraviolet region $175.85 \mathrm{~nm}$. 
Citation: Wallace I, Eshu OV, Chukwunonso OB, Okoro UC (2015) Synthesis and Characterization of Zinc Oxide (ZnO) Nanowire. J Nanomed Nanotechnol 6: 321. doi:10.4172/2157-7439.1000321

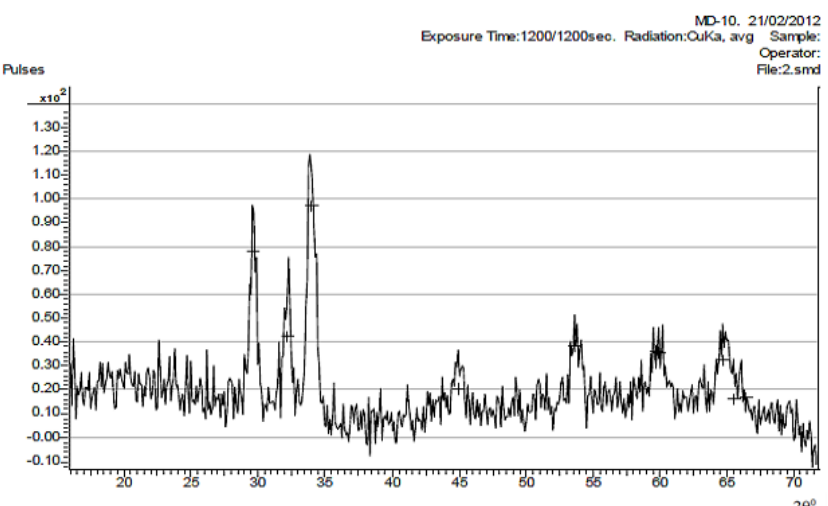

Figure 10: Chromatogram of X-ray diffraction pattern of sample.

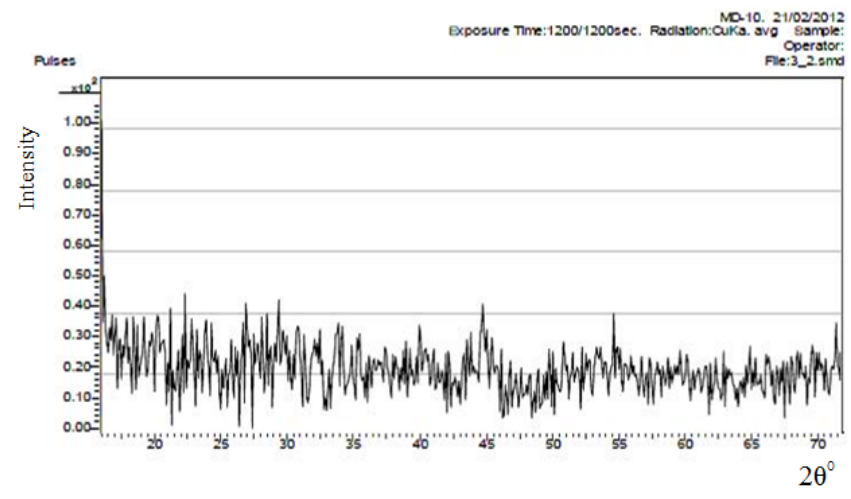

Figure 11: X-Ray diffraction pattern of W8200.

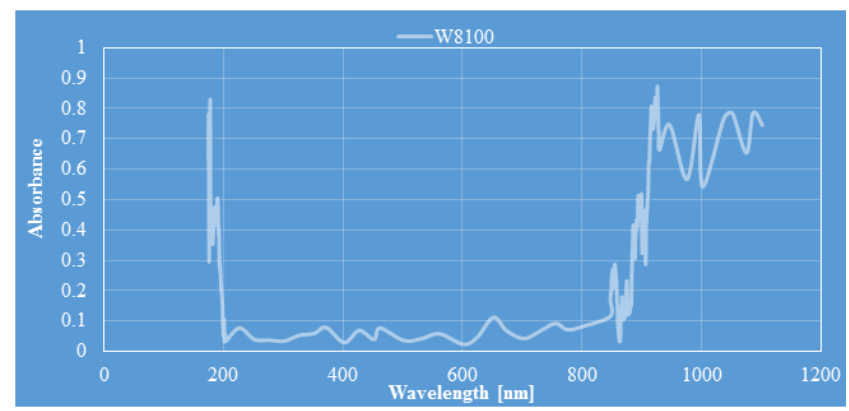

Figure 12: A plot of absorbance versus wavelength for W8100.

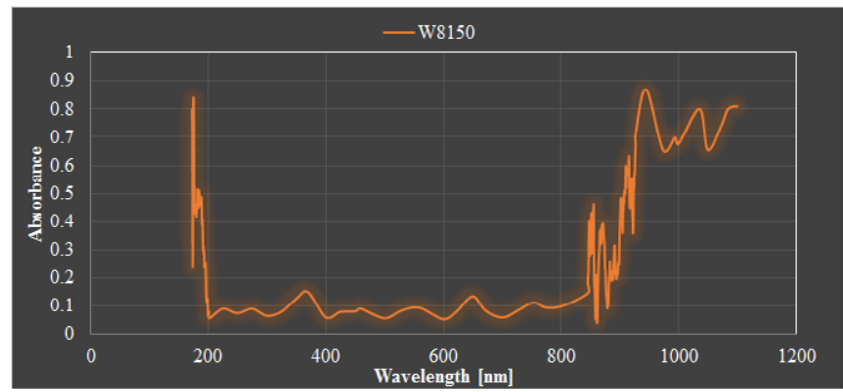

Figure 13: A plot of absorbance versus wavelength for W8150.

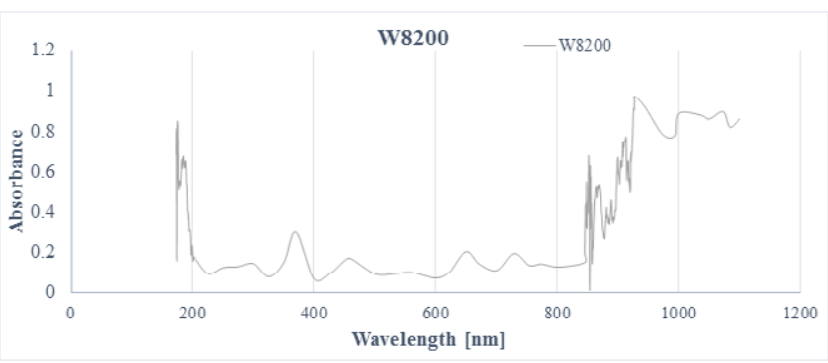

Figure 14: A plot of absorbance versus wavelength for W8200.

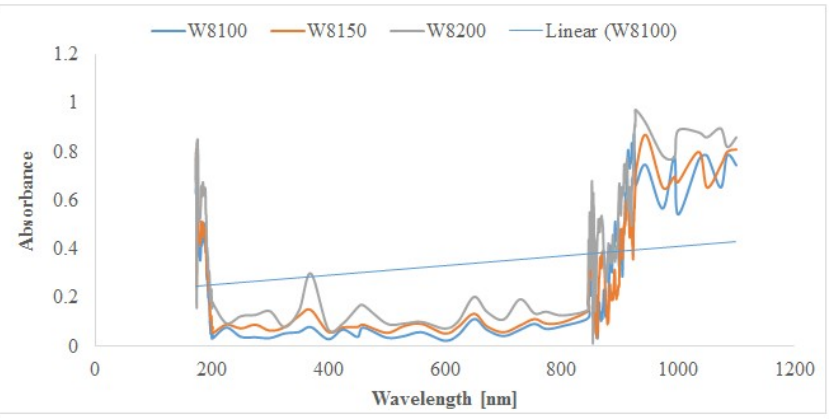

Figure 15: A correlation plot of absorbance versus wavelength for W8100 W8150 and W8200 with series trendline of W8100.

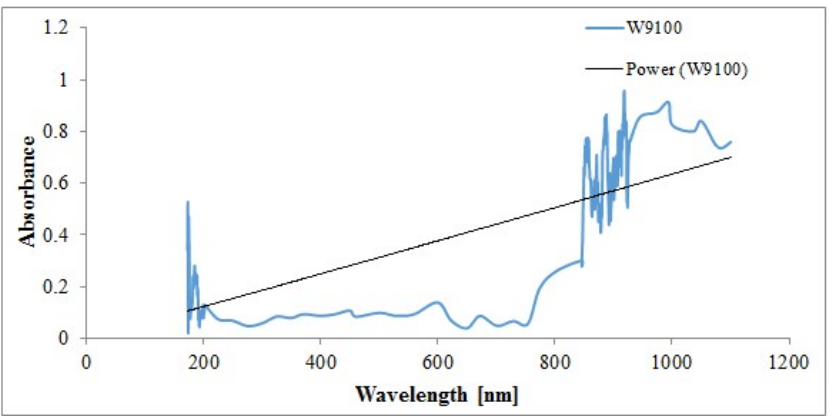

Figure 16: A plot of absorbance versus wavelength for W9100.

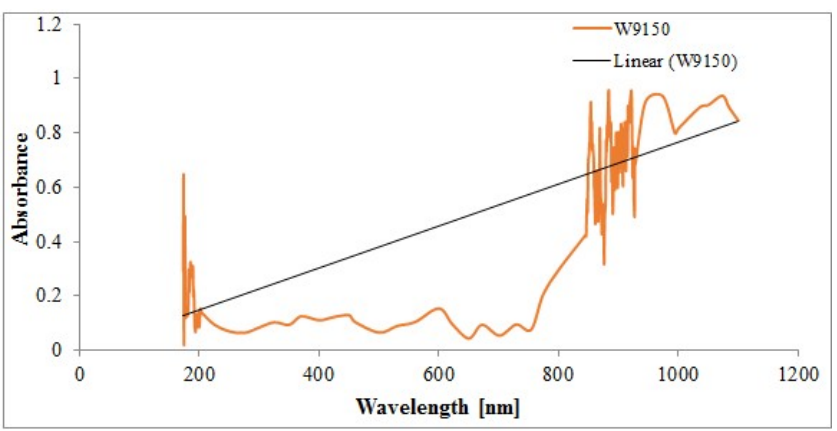

Figure 17: A plot of absorbance versus wavelength for W9150.

However, the absorbance decreases gradually in the visible region with gradual increment to infrared region. Transmittance, $\mathrm{T}$ is in contrast to the absorbance of the nanowire as it decreased with 


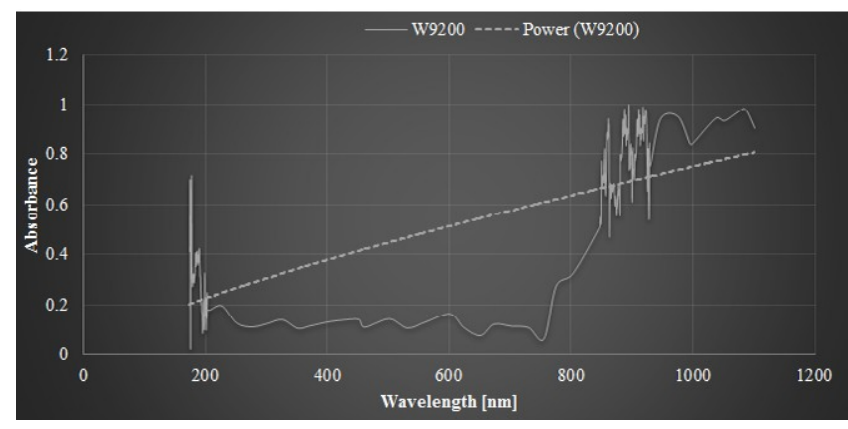

Figure 18: A plot of absorbance versus wavelength for W9200, where the trendine indicates the power.

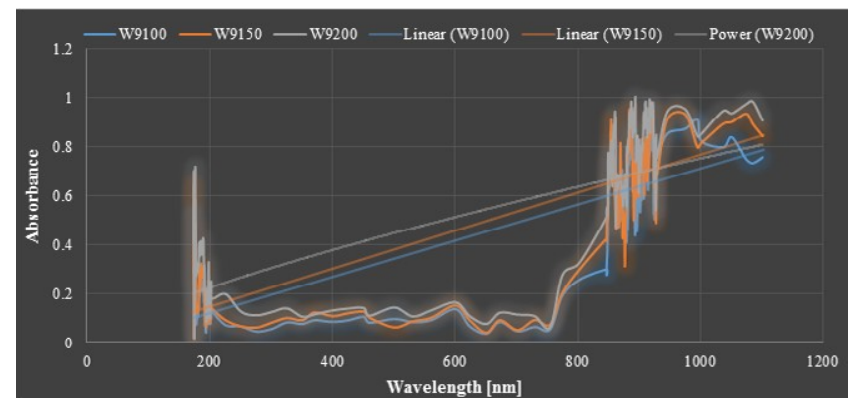

Figure 19: A correlation plot of absorbance versus wavelength for W9100 W9150 and W9200.

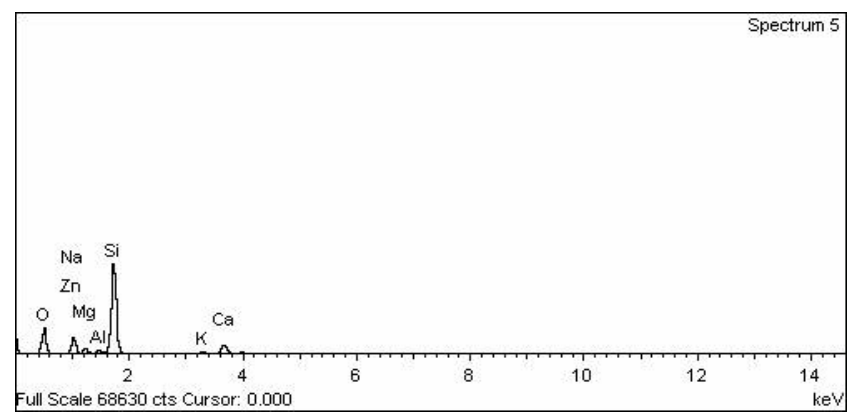

Figure 20: EDX spectrum of $\mathrm{W} 8100$ grown at $\mathrm{pH}$ of 8.1 .

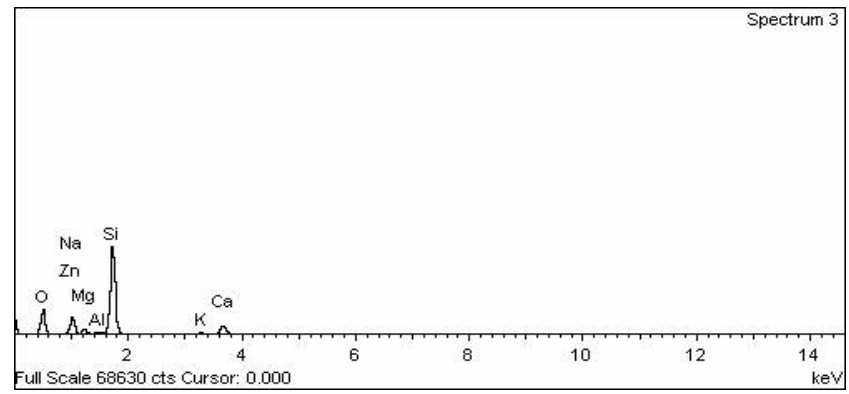

Figure 21: EDX spectrum of W9100 grown at $\mathrm{pH}$ of 9.0 .

increased absorbance.

The correlation plot of absorbance versus wavelength in Figures 15-19 showed a gradual increment in absorbance with increase in annealing temperature. The linear curves indicate the linear forecast of the respective samples. At $\mathrm{pH} 8.1$, the absorbance was $0.82,0.84$ and 0.85 at $100^{\circ} \mathrm{C}, 150^{\circ} \mathrm{C}$ and $200^{\circ} \mathrm{C}$ respectively while at $\mathrm{pH} 9.0$, the absorbance was $0.46,0.64$ and 0.71 at $100^{\circ} \mathrm{C}, 150^{\circ} \mathrm{C}$ and $200^{\circ} \mathrm{C}$ respectively. Its high absorbance in the ultraviolet region suggest that it can be used as solar harvester for trapping solar energy for photovoltaic panel which is capable of converting sunlight radiation directly to electricity for commercial or industrial purpose. The compositional study of the deposited $\mathrm{ZnO}$ nanowire was carried out by energy dispersive $\mathrm{X}$-ray (EDX) at a potential difference of $14 \mathrm{KV}$. The spectra reveal peaks, which contain both elemental compositions of glass substrate and the deposited nanowire. Each element has a unique atomic structure and binding energy. At rest, an atom within the sample contains ground state (or unexcited) electrons in discrete energy levels or electron shells bound to the nucleus. The incident beam excites an electron in an inner shell, ejecting it from the shell while creating an electron hole where the electron is. An electron from an outer, higher-energy shell then fills the hole, and the difference in energy between the higher-energy shell and the lower energy shell releases in the form of an X-ray. The number and energy of the X-rays emitted from a specimen is a characteristic of an element allowing unique sets of peaks on its X-ray spectrum. The spectra were the same for all the samples. Shown in Figures 18 and 19 are EDX result of sample W8100 and W9100.

The composition by weight of the elements present in both the nanowire and the glass substrate are as shown in the table above. The elemental composition from the Table 4 above further confirmed the presence of Zinc (29.16\%) and Oxygen (36.28\%) which is the constituent of Zinc oxide nanowire (Table 8$)$.

\section{Conclusion}

This study showed that a well align $\mathrm{ZnO}$ nanowire can be grown by chemical bath deposition technique at normal $\mathrm{pH} 8.1$ in the bath solution and optimized to form $\mathrm{ZnO}$ nanowire with top surface of hexagonal shape. This study further revealed that the crystallite size and the absorbance of the nanowire increase with increased annealing temperature. Its high absorbance in the ultraviolet region suggest its application as solar harvester for trapping solar energy for photovoltaic panel with the capacity of converting sunlight radiation directly to electricity for commercial and industrial purpose.

\section{Recommendations}

The production and characterization of $\mathrm{ZnO}$ nanowire is of considerable importance to nanotechnology and the world at large due to its unique properties. We therefore recommend the following: $\mathrm{pH} 8.1$ (original bath solution $\mathrm{pH}$ ) is the optimum $\mathrm{pH}$ for the growth of $\mathrm{ZnO}$ nanowire with chemical bath deposition method, in order to reproduce this result, for precautionary measure, the substrate upon which nanowire is to be grown must be kept free of contamination from bare hands, dust particles and other contaminants, after the growth, the substrate containing the deposited nanowire must be washed slowly allowing distilled water from syringe to drop on it and drip to dryness in air before annealing. Finally, during annealing, the digital temperature regulation oven must first be initialized by setting it to the required temperature and allowing it for some minutes to attain the specified temperature before the introduction of the nanowire and timed.

\section{References}

1. Elias J, Tena-Zaera R, Guillaume-Yangshu W, Le'vy-Cle'ment C (2008) Conversion of $\mathrm{ZnO}$ nanowires into nanotubes with Tailored dimensions. Chem Mater 20: 6633-6637. 
Citation: Wallace I, Eshu OV, Chukwunonso OB, Okoro UC (2015) Synthesis and Characterization of Zinc Oxide (ZnO) Nanowire. J Nanomed Nanotechnol 6: 321. doi:10.4172/2157-7439.1000321

2. Tong $Y$, Liu Y, Shao C, Liu Y, Xu C et al. (2006) Growth and optical properties of faceted hexagonal ZnO nanotubes. J Phys Chem B 110: 14714-14718.

3. Xing YJ, Xi ZH, Xue ZQ, Zhang XD, Song JH, et al. (2003) Optical properties of the $\mathrm{ZnO}$ Nanotubes synthesized via vapor phase growth. Appl Phys Let 83: 1689.

4. Huang $\mathrm{MH}$, Mao S, Feick $\mathrm{H}$, Yan $\mathrm{H}$, Wu $\mathrm{Y}$, et al. (2001) Room-temperature ultraviolet nanowire nanolasers. Science 292: 1897-1899.

5. Lee J, Park K, Kang Ml, Park I, Kim S, et al. (2003) ZnO nanomaterials synthesized from thermal evaporation of ballmilled $\mathrm{ZnO}$ powders. J Cryst Growth 254: 423-431.

6. Liao L, Lin YC, Bao M, Cheng R, Bai J, et al. (2010) High-speed graphene transistors with a self-aligned nanowire gate. Nature 467: 305-308.

7. Na SI, Kim SS, Hong WK, Park JW, Jo J, et al. (2008), Fabrication of TiO2 nanotubes by using electrodeposited $\mathrm{ZnO}$ nanorod template and their application to hybrid solar cells. Electrochimica Acta 53: 2560-2566.

8. Kis A, Mihailovic D, Remskar M, Mrzel A, Jesih A, et al. (2003) Shear and Young's Moduli of $\mathrm{MoS}_{2}$ Nanotube Ropes. Advanced Materials 15: 733.

9. Levi R, Bar-Sadan M, Albu-Yaron A, Popovitz-Biro R, Houben L, et al. (2010) Hollow $\mathrm{V}(2) \mathrm{O}(5)$ nanoparticles (fullerene-like analogues) prepared by laser ablation. J Am Chem Soc 132: 11214-11222.

10. Xiang B, Wang P, Zhang X, Dayeh SA, Aplin DP, et al. (2007) Rational synthesis of p-type zinc oxide nanowire arrays using simple chemical vapor deposition. Nano Lett 7: 323-328.

11. Liu, Mintang (2010) Synthesis of $\mathrm{ZnO}$ nanowires and applications as gas sensors. J Appl Phys 93: 1961-1965.

12. Izaki M (2002) Light-assisted chemical deposition of highly (0001) oriented zinc oxide film. Chem Commun (Camb) 476-477.

13. Krause M, Mucklich A, Zak A, Seifert G, Gemming S (2011) High resolution TEM study of WS2 nanotubes. Phys Status Solidi B 248: 2716-2719.

14. Hochbaum Al, Yang $P(2010)$ Semiconductor nanowires for energy conversion Chem Rev 110: 527-546.

15. Fan Z, Ruebusch DJ, Rathore AA, Kapadia R, Ergen O, et al. (2009) Challenges and prospects of Nano pillar-based solar cells. Nano Res 2: 829-43.

16. Yang LL (2008) Zinc oxide nanowire; controlled low temperature growth and some electrochemical and optical devices.

17. Cao G, Liu D (2008) Template-based synthesis of nanorod, nanowire, and nanotube arrays. Adv Colloid Interface Sci 136: 45-64.

18. Xu LF, Liao Q, Zhang JP, Ai XC, Xu DS (2007) Single-crystalline ZnO nanotube arrays on conductive glass substrates by selective dissolution of electrodeposited ZnO nanorods. J Phys Chem C 111: 4549-4552.

19. Yu QJ, Fu W, Yu CL, Yang HB, Wei RH, et al. (2007) Fabrication and optical properties of large-scale $\mathrm{ZnO}$ nanotube Bundles via a simple solution route $J$ Phys Chem C 111: 17521-17526.

20. Qiu Y, Yang S (2007) Controlled vapor-phase synthesis and application for humidity sensing. Adv Func Mater 17: 1345-1352.

21. Wang WZ, Zeng BQ, Yang J, Poudel B, Huang JY, et al. (2006) Aligned ultralong $\mathrm{ZnO}$ anobelts and their Enhanced Field Emission Adv Mate 18: 3275 3278.

22. Greene LE, Yuhas BD, Law M, Zitoun D, Yang P (2006) Solution-grown zinc oxide nanowires. Inorg Chem 45: 7535-7543.

23. Sun Y, Fuge GM, Fox NA, Riley DJ, Ashfold MNR (2005) Low-temperature solution growth of $\mathrm{ZnO}$ nanotube arrays. Adv Mater 17: 2477-2481.

24. Lincot D (2005) Electrochemical growth of CulnSe $e_{2}$ thin film on differen substrate from alkaline medium. Thin Solid Films 487: 40-48.

25. Sun Y, Fuge GM, Ashfold MNR (2004) Growth of aligned ZnO nanorod arrays by catalyst-free pulsed laser deposition methods. Chem Phys Lett 396: 21-26.
26. Wang ZL (2004) Functional oxide nanobelts: Materials, properties and potential applications in nanosystems and biotechnology. Annu Rev Phys Chem 55: $159-196$.

27. Li J, Zhao D, Meng X, Zhang Z, Zhang J, et al. (2006) Enhanced ultraviolet emission from $\mathrm{ZnS}$-coated $\mathrm{ZnO}$ nanowires fabricated by self-assembling method. J Phys Chem B 110: 14685-14687.

28. Govender K, Boyle DS, Kenway PB, O'Brien P (2004) Phase transformation and resistivity of dumbbell-like $\mathrm{ZnO}$ microcrystals under high pressure. J Mater Chem 14: 2575

29. Nuli YN, Zhao SL, Qin QZ (2003) Nanorystalline tin oxides and nickel oxide film anodes for Li-ion batteries. Power Sources 114: 113-120.

30. Vayssieres $L$ (2003) Growth of arrayed nanorods and nanowires of $\mathrm{ZnO}$ from aqueous solutions. Adv Mater 15: 464-466.

31. Zhang D, Li C, Liu X, Han S, Tang T, et al. (2003) Doping dependent NH sensing of indium oxide nanowires. Applied Physics Letters 83: 1845.

32. Wu JJ, Liu SC (2002) Low-temperature growth of well-aligned $\mathrm{ZnO}$ nanorods by chemical vapor deposition. Adv Mater 14: 215-218.

33. Kind $H$, Yan $H$, Messer B, Law M, Yang $P$ (2002) Nanowire ultraviolet photodetectors and optical switches. Adv Mate 14: 158-160.

34. Look DC, Hemsky JW, Sizelove JR (1999) Residual native shallow donor in ZnO. Physical Review Letters 82: 2552.

35. Gudiksen MS, Lauhon LJ, Wang J, Smith DC, Lieber CM (2002) Growth of nanowire superlattice structures for nanoscale photonics and electronics. Nature 415: 617-620.

36. Pan ZW, Dai ZR, Wang ZL (2001) Nanobelts of semiconducting oxides. Science 291: 1947-1949.

37. Vayssieres L, Keis K, Lindquist SE, Hagfeldt A (2001) Purpose-built anisotropic metal oxide material: 3D Highly oriented microrod array of $\mathrm{ZnO}$. J Phys Chem B 105: 3350-3352

38. Cui Y, Wei Q, Park H, Lieber CM (2001) Nanowire nanosensors for highly sensitive and selective detection of biological and chemical species. Science 293: $1289-1292$.

39. Niesen TP, De Guire MR (2001) Particle growth and particle surface interactions during low-temperature deposition of ceramic thin films. J Electroceram 6: 169

40. Tian Q, Wang Q, Xie Q, Li J (2010) Aqueous solution preparation, structure and magnetic properties of Nano-Granular $\mathrm{Zn}(\mathrm{x}) \mathrm{Fe}(3-\mathrm{x}) \mathrm{O}(4)$ Ferrite Films. Nanoscale Res Lett 5: 1518-1523.

41. Boyle DS, Bayer A, Heinrich MR, Robbe O, Brien PO (2000) Characterization of $\mathrm{ZnO}$ thin films grown by chemical bath deposition. Thin Solid Films 150: 361

42. Reynolds DC, Look DC, Jogai B (1996) Optically pumped ultraviolet lasing from ZnO. Solid State Communication 99: 873-875.

43. (2014) Nanowire. Wikipedia.

44. Fuller ML (1929) A Method Of Determining The Axial Ratio Of A Crystal From $X$-Ray Diffraction Data: The Axial Ratio And Lattice Constants Of Zinc Oxide. Science 70: 196-198. 